\title{
Simultaneous Determination of Ethidimuron, Methabenzthiazuron, and Their Two Major Degradation Products in Soil
}

\author{
Florence Lagarde, ${ }^{*} \dagger$ Thomas Puetz, ${ }^{\S}$ Joachim Dressel, ${ }^{\S}$ and Fritz Fuehr ${ }^{\S}$ \\ Laboratoire des Sciences Analytiques, UMR 5180 CNRS-UCBL, bât CPE 43, boulevard du 11 \\ novembre 1918, 69622 Villeurbanne cédex, France, and Institute of Chemistry and Dynamics of the \\ Geosphere, ICG IV: Agrosphere, Forschungzentrum Jülich GmbH, D-52425 Jülich, Germany
}

\begin{abstract}
An analytical method has been developed for the quantification of two herbicides (ethidimuron and methabenzthiazuron) and their two main soil derivatives. This method involves fluidized-bed extraction (FBE) prior to cleanup and analysis by reverse-phase liquid chromatography with UV detection at $282 \mathrm{~nm}$. FBE conditions were established to provide efficient extraction without degradation of the four analytes. ${ }^{14} \mathrm{C}$-labeled compounds were used for the optimization of extraction and purification steps and for the determination of related efficiencies. Extraction was optimal using a fexIKA extractor operating at $110^{\circ} \mathrm{C}$ for three cycles (total time $=95 \mathrm{~min}$ ) with $75 \mathrm{~g}$ of soil and $150 \mathrm{~mL}$ of a $60: 40 \mathrm{v} / \mathrm{v}$ acetone/water mixture. Extracts were further purified on a $500 \mathrm{mg}$ silica SPE cartridge. Separation was performed on a $\mathrm{C}_{18}$ Purosphere column $\left(250 \mathrm{~mm} \times 4 \mathrm{~mm}\right.$ i.d.), at $0.8 \mathrm{~mL} \mathrm{~min}^{-1}$ and $30{ }^{\circ} \mathrm{C}$ with an elution gradient made up of phosphoric acid aqueous solution (pH 2.2) and acetonitrile. Calibration curves were found to be linear in the $0.5-50 \mathrm{mg} \mathrm{L}^{-1}$ concentration range. Besides freshly spiked soil samples, method validation included the analysis of samples with aged residues. Recovery values, determined from spiked samples, were close to $100 \%$. Limits of detection ranged between 2 and 3 $\mu \mathrm{g} \mathrm{kg}^{-1}$ of dry soil and limits of quantification between 8 and $10 \mu \mathrm{g} \mathrm{kg}^{-1}$ of dry soil. An attempt to improve these performances by using fluorescence detection following postcolumn derivatization by orthophthalaldehyde-mercaptoethanol reagent was unsuccessful.
\end{abstract}

KEYWORDS: Ethidimuron; methabenzthiazuron; metabolites; soils; fexIKA extraction; SPE purification; HPLC-DAD; fluorescence

\section{INTRODUCTION}

Prediction of groundwater contamination by pesticides requires a qualitative and quantitative understanding of solute transport processes in soil. As a risk assessment, tool lysimeters are widely used and accepted by official European authorities and industry. Nevertheless, more information on the validity of these test systems is needed, especially in the case of heavy soils. To improve knowledge of relevant processes in lysimeters and validate the transfer of lysimeter data to the field/region scale, an extensive field experiment was set up in JülichMerzenhausen (Germany) including lysimeters and small plots at the same time (1). Two pesticides, ethidimuron (ETD) and methabenzthiazuron (MBT), were chosen as test substances to cover the whole spectrum from immobile to mobile translocation behavior and applied according to good agricultural practice to determine the flow and transport processes in soils.

* Author to whom correspondence should be addressed (telephone 0033472432626; fax 0033472448319; e-mail florence.lagarde@ univ-lyon1.fr)

CNRS-UCBL.

$\S$ Forschungzentrum Jülich GbmH.
Ethidimuron and methabenzthiazuron are urea-derived herbicides known for their plant growth inhibitory effects (2). Many formulated products containing ETD or MBT have been commercialized for more than 30 years. ETD is a total herbicide, whereas MBT is a selective compound for the control of broadleaved weeds and grasses in cereals, legumes, maize, garlic, and onions (3). The fate of MBT in the soil/water/plant environment has been intensively studied through laboratory $(4-6)$, lysimeter $(7,8)$, or field experiments $(9-12)$. MBT is relatively stable in soil owing to its rapid and firm binding to humus components. It is slowly degraded, predominantly by microorganisms. Although MBT degradation by isolated strains may produce other compounds (13-15), demethyl-methabenzthiazuron (A-MBT) is the main metabolite detected in environmental conditions $(5,8-10)$. Contrary to MBT, ETD is slightly retained by soils (16). Its degradation by microorganisms is also very slow and gives essentially demethyl-ethidimuron (A-ETD) (17). Both herbicides and their corresponding principal degradation products are shown in Figure 1.

To carry out the project, a reliable and accurate method for the simultaneous determination of the four compounds, MBT, A-MBT, ETD, and A-ETD, in soil samples was consequently 


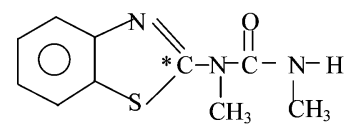

MBT

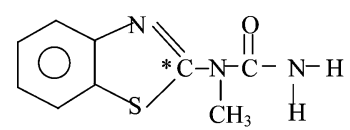

A-MBT

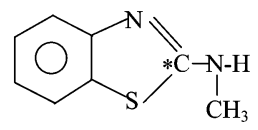

I

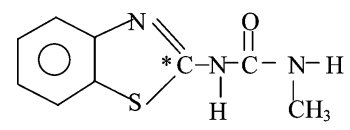

II

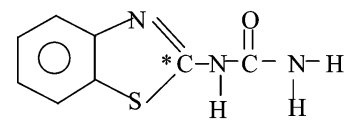

III

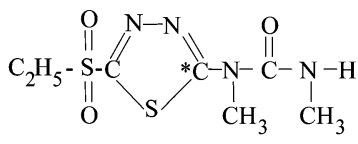

ETD

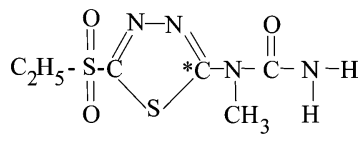

A-ETD

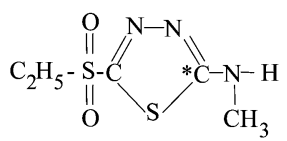

IV

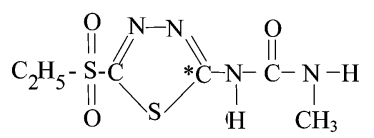

V

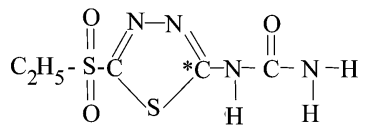

VI

Figure 1. Chemical formulas of MBT, ETD, and some degradation products. An asterisk $(*)$ indicates the position of ${ }^{14} \mathrm{C}$-labeled carbons in active molecules.

needed. To our knowledge, only three publications had already been dedicated to the determination of ETD in environmental samples $(18-20)$. Two were focused on the analysis of water samples by HPLC-DAD $(18,19)$, whereas only one dealt with soil analysis by GC with nitrogen detection and proposed the simultaneous quantification of A-ETD (20). Nevertheless, a total of $\approx 1 \mathrm{~L}$ of toxic solvents (acetonitrile, methanol, acetone) was required for both extraction and cleanup steps. Moreover, recoveries were not always quantitative (from 70 to $99 \%$ depending on the nature of the soil and on spiking concentrations). As a consequence, a more efficient way to determine A-ETD and ETD in soil had to be found.

With regard to MBT, many analytical methods had already been proposed for its quantification (alone or most often together with other phenylurea pesticides) in various matrices: mainly natural waters, but also fruits, vegetables, and soils. They were based on immunochemical affinity (21) or consisted of gas or liquid chromatographic separation. Due to their thermal instability, urea pesticides are difficult to analyze directly by gas chromatography (22). Some authors proposed to add a prederivatization step and quantification by mass spectrometry, nitrogen-phosphorus, or electron-capture detectors $(23,24)$. Nevertheless, chemical derivatization is time-consuming and generates interferences or analyte losses. As a consequence, numerous works were published using either capillary electrophoresis (25) or high-performance liquid chromatography (2530 ). Although mass spectrometry and tandem mass spectrometry offer high selectivity and sensitivity and have been successfully coupled to HPLC for the determination of pesticides and their metabolites in environmental samples (26-28), diode array detection is by far less expensive and remains commonly used $(19,26,27,29-32)$. Among these last seven publications, only two are concerned with the quantification of MBT in soil (30, 32), but none deals with A-MBT.

In this work, we evaluated fluidized-bed extraction (FBE) to extract A-ETD, ETD, A-MBT, and MBT from soil samples. A purification on $\mathrm{SiOH}$ cartridges followed by the HPLC separation of the four compounds using a reverse phase $\mathrm{C}_{18}$ column was optimized. The performance of the resulting method was finally determined.

\section{MATERIALS AND METHODS}

Chemicals. MBT (1-benzothiazol-2-yl-1,3-dimethyl-urea, 99.6\%), ETD [1-(5-ethylsulfonyl-1,3,4-thiadiazol-2-yl)-1,3-dimethylurea, 99.8\%], A-ETD (96.9\%), and A-MBT (99\%) as well as ${ }^{14} \mathrm{C}$-labeled compounds [benzothiazolyl-2- $\left.{ }^{14} \mathrm{C}\right] \mathrm{MBT}(>99.9 \%)$ and $\left[\right.$ thiadiazol-2- $\left.{ }^{14} \mathrm{C}\right] \mathrm{ETD}(>98 \%)$ were supplied by Bayer AG (Monheim, Germany).

HPLC-grade solvents, including acetonitrile (ACN), methanol $(\mathrm{MeOH})$, ethyl acetate (AcOEt), acetone, toluene, and dichloromethane (DCM) were purchased from Merck (Darmstadt, Germany). Ultrapure water was obtained from a Milli-Q system (Millipore, Billerica, MA).

Phosphoric acid $(85 \%)$, orthophthalaldehyde (OPA, >99\%), mercaptoethanol (MERC, $>99 \%$ ), sodium tetraborate decahydrate $(>99.5 \%)$, and $\mathrm{NaOH}(>99 \%)$ were of analytical grade and provided by Merck.

Instrumentation. HPLC consisted of an M480 G liquid chromatograph from Gynkotek (Munich, Germany) with a Gina 160 automatic injector and an STH 585 A column oven. HPLC was coupled with a UVD 320 S diode array detector (Gynkotek) and an LB 509 radioactivity monitor (Berthold). The separation was performed using a Purosphere RP18 100, $5 \mu \mathrm{m}, 250 \times 4 \mathrm{~mm}$ i.d. column (Merck) equipped with a guard column packed with the same material.

For the fluorescence detection tests, the diode array detector was disconnected and a homemade Teflon FEP tube $(3$ or $6 \mathrm{~m} \times 0.5 \mathrm{~mm}$ i.d. $\times 1 / 16$ in. o.d.) knitted around a low-pressure high-power NNI 40/ 20 lamp (Heraeus, Hanau, Germany) was connected to the outlet of the HPLC column. It was used for the UV degradation of the compounds. The amines generated were mixed with OPA-MERC reagent via a zero-volume mixing-tee placed just after the photoreactor and allowed to react in a second Teflon knitted coil $(3.6$ or $10 \mathrm{~m} \times$ $0.3 \mathrm{~mm}$ i.d. $\times 1 / 16$ in. o.d.). Detection of the fluorescent derivatives was carried out using a Jasco FP 1520 (Gross-Umstadt, Germany) instrument. Excitation and emission wavelengths were fixed at 340 and $455 \mathrm{~nm}$, respectively.

For residue confirmation, HPLC was coupled to a triple-quadrupole mass spectrometer TSQ Quantum from Thermo Finnigan equipped with an electrospray ionization source. Argon was chosen as collision gas, and detection was performed in the positive ion mode. Selected reaction monitoring (SRM) was performed on each of the protonated molecular ions $(\mathrm{m} / \mathrm{z}, 250.9,264.9,207.8$, and 221.8 for A-ETD, ETD, A-MBT, and MBT, respectively). Collision energies were set at the maximum for each transition and ranged from 24 to $58 \mathrm{~V}$.

${ }^{14} \mathrm{C}$ activity was measured in solutions (soil extracts, spiking solutions) by liquid scintillation counting using a Tri-Carb analyzer 2500 TR model after the addition of instant scintillation gel (Canberra Packard, Frankfurt, Germany).

Extracts were concentrated at $50{ }^{\circ} \mathrm{C}$ by a TurboVap II system and purified using an automated solid-phase extraction (SPE) Benchmate workstation (Zymark, Idstein, Germany) controlled by the corresponding 2.51 version software.

Preparation of Solutions. Stock solutions $\left(\approx 0.5 \mathrm{~g} \mathrm{~L}^{-1}\right)$ of individual nonlabeled ETD, MBT, A-ETD, and A-MBT were obtained by dissolving accurate amounts of the compounds in $\mathrm{ACN} / \mathrm{H}_{2} \mathrm{O} 50: 50 \mathrm{v} / \mathrm{v}$. Two stock solutions of $\left[{ }^{14} \mathrm{C}\right]-\mathrm{ETD}\left(10 \mathrm{mg} \mathrm{L}^{-1}, 27.2 \mathrm{MBq} \mathrm{L}^{-1}\right)$ and $\left[{ }^{14} \mathrm{C}\right]$-MBT (43 $\mathrm{mg} \mathrm{L}^{-1}, 2.32 \mathrm{MBq} \mathrm{L}{ }^{-1}$ ) were also prepared from radiolabeled compounds. They were preserved at $4{ }^{\circ} \mathrm{C}$ in the dark, under which conditions they were found to be stable for at least 2 months. 
Standards for HPLC $\left(0.5-50 \mathrm{mg} \mathrm{L}^{-1}\right)$ were prepared freshly by dilution of appropriate aliquots of the four nonactive mother solutions in $\mathrm{ACN} / \mathrm{H}_{2} \mathrm{O} 50: 50 \mathrm{v} / \mathrm{v}$ or in matrix.

The four solutions used in the cleanup recovery study were obtained by spiking $2 \mathrm{~mL}$ of a matrix extract with small volumes of either $\left[{ }^{14} \mathrm{C}\right]-$ MBT or $\left[{ }^{14} \mathrm{C}\right]$-ETD stock solutions or a mixture of active and nonactive ETD stock solutions.

Soil spiking solutions were prepared just before use. They were obtained, for procedure 1, by sampling adequate volumes of active and/ or nonactive mother solutions and mixing them. The resulting solutions were evaporated and redissolved in $60 \mathrm{~mL}$ of acetone. For procedure 2, $\left[{ }^{14} \mathrm{C}\right]-$ MBT and $\left[{ }^{14} \mathrm{C}\right]-$ ETD stock solutions were diluted in ultrapure water to reach the 20 or $250 \mu \mathrm{g} \mathrm{L}^{-1}$ level, respectively.

Solutions used for the OPA-MERC postcolumn derivatization were prepared as described by Luchtenfeld (33).

Soil Samples and Spiking. Samples of an orthic luvisol formed on alluvial loess (composition: $78.2 \%$ of silt, $15.4 \%$ of clay, $6.4 \%$ of sand; $\mathrm{pH} 7.2,1.2 \%$ organic matter cation exchange capacity $=11.4$ mequiv $\left.100 \mathrm{~g}^{-1}, K_{f, \mathrm{ETD}}=0.332 \mathrm{~cm}^{3} \mathrm{~g}^{-1}, K_{f, \mathrm{MBT}}=7.01 \mathrm{~cm}^{3} \mathrm{~g}^{-1}\right)$ were collected from an experimental field located in Jülich-Merzenhausen (Germany). Hand corers equipped with stainless steel sampling tubes and PVC liners (300 $\mathrm{mm} \times 35 \mathrm{~mm}$ i.d., Humax, Lucerne, Switzerland) were used to extract the first $30 \mathrm{~cm}$. Sample with naturally aged residues of $\left[{ }^{14} \mathrm{C}\right]-$ ETD and nonlabeled MBT was obtained from a small plot experiment some weeks after application and used for the optimization of extraction conditions. Uncontaminated soil was drawn from the adjacent nontreated plot. These samples were stored at $-18{ }^{\circ} \mathrm{C}$ until extraction or fortification.

Ten fortified samples were produced according to two different spiking procedures.

Spiking Procedure 1. Eight hundred gram aliquots of the wet uncontaminated soil ( $25 \%$ moisture) were spread and treated by uniform spraying of $50 \mathrm{~mL}$ of spiking solutions.. After evaporation of acetone at room temperature and homogenization of the materials using a rotating shaker, samples were allowed to age for $24 \mathrm{~h}$ at room temperature. They were dried at room temperature, shaken again, and extracted. Eight soils $(\mathrm{A}-\mathrm{H})$ were prepared following this procedure: soils $\mathrm{A}$ and $\mathrm{B}$ were spiked with single $\left[{ }^{14} \mathrm{C}\right]$-ETD at the 50.1 and 79 $\mu \mathrm{g} \mathrm{kg}^{-1}$ levels, whereas soil C contained $97.7 \mu \mathrm{g} \mathrm{kg}^{-1}$ of $\left[{ }^{14} \mathrm{C}\right]-\mathrm{MBT}$. Soils D-F included a mixture of nonactive ETD at respective concentrations of $19.3,39.8$, and $403 \mu \mathrm{g} \mathrm{kg}^{-1}$ and $\left[{ }^{14} \mathrm{C}\right]-\mathrm{MBT}$ at 15.9 , 40 , and $453 \mu \mathrm{g} \mathrm{kg}^{-1}$. The last two soils were fortified at the 30 and $160 \mu \mathrm{g} \mathrm{kg}^{-1}$ level with a mixture of A-ETD and A-MBT. Soils A-F, which all contained one radiolabeled compound (either MBT or ETD), were used to determine extraction recoveries. Soils A-H allowed evaluation of the accuracy and the precision of the overall method after correction by the extraction coefficients previously estimated. Aging experiments were carried out with soils B and C.

Spiking Procedure 2. Two soils with individual ${ }^{14} \mathrm{C}$-labeled pesticides at the $40 \mu \mathrm{g} \mathrm{kg}^{-1}$ level were prepared following a batch equilibrium method: a $100 \mathrm{~g}$ amount of uncontaminated sample was equilibrated with $500 \mathrm{~mL}$ of an aqueous solution of $\left[{ }^{14} \mathrm{C}\right]-\mathrm{MBT}\left(20 \mu \mathrm{g} \mathrm{L}^{-1}\right)$ or $\left[{ }^{14} \mathrm{C}\right]$-ETD $\left(250 \mu \mathrm{g} \mathrm{L}^{-1}\right)$ by mechanical shaking overnight at room temperature. After equilibration, the suspension was centrifuged for 30 min at $900 g$ using a Beckman GPKR apparatus (Münich, Germany), and ${ }^{14} \mathrm{C}$ activity was measured in the supernatant by LSC. The amount of sorbed analyte was calculated from the difference between this value and the activity of the initial solution. These soils were dried at room temperature and extracted.

Extraction Procedures. Prior to extraction, samples were allowed to warm (if stored at -18 or $4{ }^{\circ} \mathrm{C}$ ) and dry at room temperature and then passed through a $2 \mathrm{~mm}$ sieve. Their moisture content was determined by drying three $200 \mathrm{mg}$ aliquots of soil (accurately weighed) at $105^{\circ} \mathrm{C}$ and calculating the average loss of mass.

For the optimization of extracting conditions, two procedures were evaluated: shaking extraction at room temperature and fluidized-bed extraction operating under solvent reflux.

Cold Shaking Extraction. Twenty-five grams of soil was shaken overnight at room temperature with $150 \mathrm{~mL}$ of extractant using a reciprocating shaker model SM 25 A from Bühler (Tübingen, Germany). Acetone, acetonitrile, and methanol as well as several mixtures with water were evaluated: $\mathrm{MeOH} / \mathrm{H}_{2} \mathrm{O}$ 80:20 v/v and 60:40 v/v; acetone/ $\mathrm{H}_{2} \mathrm{O}$ 80:20 v/v, 60:40 v/v, and 40:60 v/v; azeotropic ACN/ $\mathrm{H}_{2} \mathrm{O}$ 87:13 $\mathrm{v} / \mathrm{v}$. Extractions were performed in duplicate. After extraction, the suspension was centrifuged for $30 \mathrm{~min}$ at $900 \mathrm{~g}$ using a Beckman GPKR apparatus, and the supernatant was transferred into a Turbovap flask together with $\approx 6 \mathrm{~mL}$ obtained by rinsing the vessel with $3 \times 2 \mathrm{~mL}$ of solvent. The extracts were concentrated at $50{ }^{\circ} \mathrm{C}$ until damp residues were obtained (and not to dryness to avoid degradation or loss of the compounds). Those residues were dissolved in $2 \mathrm{~mL}$ of $\mathrm{ACN} / \mathrm{H}_{2} \mathrm{O} 50$ : $50 \mathrm{v} / \mathrm{v}$, and two aliquots of $25 \mu \mathrm{L}$ were sampled for the determination of $\left[{ }^{14} \mathrm{C}\right]$-ETD activity. The rest was transferred to HPLC vials for direct chromatographic analysis using ${ }^{14} \mathrm{C}$ activity detection. Extracts were not purified. This set of experiments allowed the effect of water content on ETD extraction to be studied and the nature and percentage of ETD degradation products present in the soil before extraction (natural degradation compounds) to be determined.

Fluidized-Bed Hot Extractions. Hot extractions were performed using a fluidized-bed fexIKA 200 extractor (Ika-Labortechnik, Staufen, Germany). The principle of fluidized-bed extraction was already described elsewhere (33). With the configuration used eight extractions could be carried out simultaneously.

Taking into account results of cold extractions, only $\mathrm{MeOH} / \mathrm{H}_{2} \mathrm{O}$ 60:40 v/v, acetone $/ \mathrm{H}_{2} \mathrm{O} 60: 40 \mathrm{v} / \mathrm{v}$, and $\mathrm{ACN} / \mathrm{H}_{2} \mathrm{O}$ 87:13 v/v were investigated as extracting systems. Seventy-five grams of soil was accurately weighed and deposited on the frit of the column. The extraction flask was filled with the appropriate volume of organic solvent ( $90 \mathrm{~mL}$ of acetone or methanol, $130 \mathrm{~mL}$ of ACN) and connected to the column, and the extraction program was started. When the temperature of the heating block reached $\approx 35^{\circ} \mathrm{C}$, water $(60$ or $20 \mathrm{~mL})$ was added onto the soil to wet the sample properly and help the extraction of the more polar compounds. Eight simultaneous extractions were performed for each solvent mixture. Six were run for three cycles and two for four cycles in order to determine the optimal number of cycles. After extraction, the vessels were allowed to cool to room temperature, and solutions were transferred to a TurboVap glass. Further treatment and characterizations were identical to those applied to cold shaking extracts except that HPLC analysis was performed using both $\mathrm{UV}$ and ${ }^{14} \mathrm{C}$ activity detections. This allowed systems inducing ETD thermal degradation to be identified and the best extractant for both ETD and MBT to be found.

Preliminary experiments consisting of a three-cycle extraction of the uncontaminated soil had been carried out for each solvent mixture to define the best fexIKA extractor parameters. Starting parameter settings were: a heat-up temperature of $110{ }^{\circ} \mathrm{C}$ for acetone/ $\mathrm{H}_{2} \mathrm{O} 60: 40$ $\mathrm{v} / \mathrm{v}$ and $\mathrm{MeOH} / \mathrm{H}_{2} \mathrm{O} 60: 40 \mathrm{v} / \mathrm{v}$ extractions and of $90{ }^{\circ} \mathrm{C}$ for $\mathrm{ACN} / \mathrm{H}_{2} \mathrm{O}$ $87: 13 \mathrm{v} / \mathrm{v}$, selected according to the boiling points of the extractants, and a cooling temperature of $25^{\circ} \mathrm{C}$ to establish the required differential filtration pressure. The aim was to achieve a quite complete but not total evaporation of the solvent at the end of the heating step and a total duration per extraction cycle not exceeding $45 \mathrm{~min}$. Temperatures had to be increased to $115^{\circ} \mathrm{C}$ for $\mathrm{MeOH} / \mathrm{H}_{2} \mathrm{O} 60: 40 \mathrm{v} / \mathrm{v}$ and to $95{ }^{\circ} \mathrm{C}$ for $\mathrm{ACN} / \mathrm{H}_{2} \mathrm{O} 87: 13 \mathrm{v} / \mathrm{v}$ to achieve this goal. For an optimal filtration, cooling temperature was maintained at $25^{\circ} \mathrm{C}$ for the first cycle and set $5{ }^{\circ} \mathrm{C}$ below for the two others.

Optimal extraction conditions were finally obtained with the fexIKA system running for three cycles at $110{ }^{\circ} \mathrm{C}$ with the acetone/water 60 : $40 \mathrm{v} / \mathrm{v}$ mixture. Heating times as well as cooling temperature were 25 min, $4 \mathrm{~min}$, and $25^{\circ} \mathrm{C}$, respectively, for the first cycle and $35 \mathrm{~min}, 4$ $\min$, and $20^{\circ} \mathrm{C}$ for subsequent cycles. Extracts required for the other parts of the work, including matrix extracts from the uncontaminated soil, were consequently prepared in those conditions.

Cleanup Procedure. One or several $0.5 \mathrm{~mL}$ aliquots of the raw extracts were evaporated and redissolved in $6 \mathrm{~mL}$ of toluene and 20 $\mu \mathrm{L}$ of ultrapure water for purification. Five hundred milligram silica SPE cartridges (Macherey \& Nagel, Düren, Germany) were conditioned with $5 \mathrm{~mL}$ of AcOEt and $10 \mathrm{~mL}$ of toluene by the Benchmate automate. Each sample was vortexed in a $20 \mathrm{~mL}$ glass tube for $30 \mathrm{~s}$ and passed through one cartridge for purification. The sample tube was then rinsed with $3 \mathrm{~mL}$ of toluene that was subsequently transferred to the cartridge. This latter was washed with $10 \mathrm{~mL}$ of DCM, and analytes were finally recovered with $10 \mathrm{~mL}$ of AcOEt/DCM 60:40 v/v. Flow rates were 0.5 
$\mathrm{mL} \mathrm{s}^{-1}$ for aspiration, $0.25 \mathrm{~mL} \mathrm{~s}^{-1}$ for conditioning, and $0.05 \mathrm{~mL} \mathrm{~s}^{-1}$ for column loading/rinsing/elution. The entire system was washed with $5 \mathrm{~mL}$ of AcOEt at the end of the procedure to prevent crosscontaminations. The eluates were evaporated at $50{ }^{\circ} \mathrm{C}$ using the Turbovap apparatus and residues redissolved in $\mathrm{ACN} / \mathrm{H}_{2} \mathrm{O} 50: 50 \mathrm{v} / \mathrm{v}$ for LSC and/or HPLC analysis.

Chromatographic Separation. For HPLC-DAD analysis, the optimal separation was obtained using $\mathrm{ACN}$ and water at $\mathrm{pH} 2.2$ (adjusted with orthophosphoric acid) as solvents for mobile phase and the following step gradient: $5 \% \mathrm{ACN}$ for $5 \mathrm{~min}$, linear increase to $90 \% \mathrm{ACN}$ in $26 \mathrm{~min}, 90 \%$ for $4 \mathrm{~min}$, linear decrease to $5 \%$ in $7 \mathrm{~min}$. The pesticides were separated in those conditions, at $30{ }^{\circ} \mathrm{C}$ and 0.8

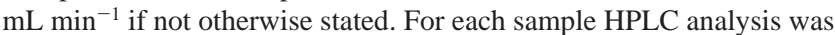
performed at least in duplicate. The injected volume was $25 \mu \mathrm{L}$. A wavelength of $282 \mathrm{~nm}$ was chosen as recording wavelength as UV absorbance is maximal at this value for both A-ETD and ETD and close to the maximum for A-MBT and MBT.

These conditions were modified when OPA-MERC postcolumn derivatization with fluorescence detection was tested. In that case, the mobile phase was composed of methanol and water and the gradient was as follows: $15 \% \mathrm{MeOH}$ for $10 \mathrm{~min}$, linear increase to $70 \% \mathrm{MeOH}$ in $50 \mathrm{~min}, 70 \%$ for $10 \mathrm{~min}$, and linear decrease to $15 \%$ in $15 \mathrm{~min}$. Optimal separation and fluorescence signals were obtained at $40{ }^{\circ} \mathrm{C}$, with flow rates of $0.3 \mathrm{~mL} \mathrm{~min}^{-1}$ for HPLC and $0.03 \mathrm{~mL} \mathrm{~min}^{-1}$ for the OPA-MERC reagent.

HPLC-MS-MS analyses were also performed at a lower flow rate $\left(0.25 \mathrm{~mL} \mathrm{~min}^{-1}\right)$ with a modified gradient: $30 \% \mathrm{ACN}$ for $5 \mathrm{~min}$, linear increase to $100 \% \mathrm{ACN}$ in $8 \mathrm{~min}, 100 \%$ for $10 \mathrm{~min}$, linear decrease to $30 \%$ in 1 min. $\mathrm{H}_{2} \mathrm{O}$ contained $0.1 \%$ methanol and $0.1 \%$ formic acid instead of phosphoric acid. One hundred microliters was injected.

Evaluation of Method Performance. Characteristics of the HPLC$D A D$ Method. Reproducibility of retention times was calculated from 10 injections on three different days of a $25 \mathrm{mg} \mathrm{L}^{-1}$ aqueous standard solution. To establish the linearity of the response and evaluate the possible matrix effect, two calibration curves were built for each compound from standards prepared at seven different concentration levels $\left(0.5,1,2.5,5,10,25\right.$, and $\left.50 \mathrm{mg} \mathrm{L}{ }^{-1}\right)$ in $\mathrm{ACN} / \mathrm{H}_{2} \mathrm{O}(1: 1)$ and in matrix. Three replicate measurements were performed the same day at each level.

Extraction Recoveries. Extraction recoveries were determined at different concentrations of ETD and MBT using soils A-F. Eight extractions (respectively four extractions) were performed simultaneously for samples A and $\mathrm{D}-\mathrm{F}$ (respectively B and C). ${ }^{14} \mathrm{C}$ activity, issued from either ETD or MBT, was determined in each extract after solvent evaporation and redissolution in $2 \mathrm{~mL}$ of $\mathrm{ACN} / \mathrm{H}_{2} \mathrm{O} 50: 50 \mathrm{v} / \mathrm{v}$. Results were compared to the nominal values for recovery calculations and evaluation of the recovery correction coefficient. Standard deviations were also determined for reproducibility assessment. Four extractions of soils $\mathrm{B}$ and $\mathrm{C}$ were performed after a 5 months of storage of the samples and analyzed by LSC in order to study the effect of soil aging on extraction efficiencies.

Cleanup Recoveries. Four solutions containing individual radiolabeled pesticides $\left(0.53\right.$ and $5.2 \mathrm{mg} \mathrm{L}^{-1}$ of $\left[{ }^{14} \mathrm{C}\right]-\mathrm{MBT}, 0.77$ and $6.8 \mathrm{mg}$ $\mathrm{L}^{-1}$ of $\left[{ }^{14} \mathrm{C}\right]$-ETD) were used. About $2 \mathrm{~mL}$ of fortified extracts was prepared as described previously. Two aliquots of $200 \mu \mathrm{L}$ were sampled and analyzed by LSC to determine initial ${ }^{14} \mathrm{C}$ activity in each extract. Three aliquots of $0.5 \mathrm{~mL}$ were evaporated, and each was redissolved in $6 \mathrm{~mL}$ of toluene to be purified. Purified extracts were finally recovered in $0.5 \mathrm{~mL}$ of $\mathrm{ACN} / \mathrm{H}_{2} \mathrm{O}(1: 1)$, and ${ }^{14} \mathrm{C}$ activity was measured, which allowed calculation of the average cleanup recoveries and related standard deviations.

Precision and Accuracy of the Overall Method. The precision and accuracy of the whole method including extraction, purification, and HPLC-DAD determination were examined for each compound at different concentration levels in the $40-450 \mu \mathrm{g} \mathrm{kg}^{-1}$ range. Four of the eight extracts of soils $\mathrm{A}-\mathrm{F}$, already used to determine extraction recoveries, and four extracts of soils $\mathrm{G}$ and $\mathrm{H}$ were used for that purpose. Two $0.5 \mathrm{~mL}$ aliquots of each extract were purified and analyzed by HPLC-DAD (two injections for three consecutive days). Average recoveries and related standard deviations were calculated after correction by the average extraction efficiency. Four extracts of soils
$\mathrm{B}$ and $\mathrm{C}$ were prepared after a 6 month period of storage at $4{ }^{\circ} \mathrm{C}$. They were treated the same way and analyzed by HPLC-DAD to study the effect of soil aging on overall method accuracy.

Limits of Detection (LOD) and Quantification (LOQ). LOD and LOQ were calculated from the chromatograms of eight purified uncontaminated soil extracts, as, respectively, 3 and 10 times the standard deviation of the background noise.

\section{RESULTS AND DISCUSSION}

Soil Extraction. The objective was to achieve the most efficient extraction for the four target compounds (A-ETD, ETD, $\mathrm{A}-\mathrm{MBT}$, and MBT) without inducing their degradation and, at the same time, to avoid coextraction of interfering substances, which would lead to noninterpretable HPLC chromatograms. The traditional solid-liquid extraction techniques, Soxhlet, sonication, and shake-flask extraction, are widely used to analyze pesticides and their degradation products in soils. Nevertheless, they are generally time-consuming and require large volumes of organic solvents. Recently, a new FBE procedure has been proposed as an alternative to Soxhlet, with the advantage of lower solvent consumption, faster extraction, and full automation $(34,35)$. Its efficiency was shown to be comparable to that of other enhanced methods (microwave-assisted and accelerated solvent extractions) for the extraction of organochlorine compounds from sediments (35). It was then decided to evaluate this technique, in addition to flask-shaking extraction at room temperature (cold shaking extraction) for the extraction of ETD, MBT, and their two derivatives. Acetone, acetonitrile, and methanol were tested as organic extractants. As it is known that water may have a positive effect on extraction $(32,36)$, several mixtures with water were also investigated (azeotropic ACN/ $\mathrm{H}_{2} \mathrm{O} 87: 13 \mathrm{v} / \mathrm{v}, \mathrm{MeOH} / \mathrm{H}_{2} \mathrm{O} 80: 20 \mathrm{v} / \mathrm{v}$, and 60:40 v/v; acetone/ $\mathrm{H}_{2} \mathrm{O} 80: 20 \mathrm{v} / \mathrm{v}, 60: 40 \mathrm{v} / \mathrm{v}$, and 40:60 v/v). Experiments were carried out using a $20-30 \mathrm{~cm}$ soil layer collected in small plots some weeks after the application of $\left[{ }^{14} \mathrm{C}\right]$-ETD and nonlabeled MBT for environmental behavior studies. There were several advantages to the use of this kind of sample: (i) it contained naturally aged residues of both pesticides; (ii) a large quantity of soil containing both compounds was directly available, which avoided fastidious and long spiking procedures; (iii) the determination of total ${ }^{14} \mathrm{C}$ activity in the extracts by LSC allowed information to be obtained very rapidly about the extractability of ETD and the choice of the best extraction conditions; (iv) HPLC chromatograms of the extracts, recorded using ${ }^{14} \mathrm{C}$ radioactivity detection, allowed visualization of, very specifically and with lower detection limits than UV, ETD degradation products. Instrumental fexIKA parameters were set, for each extracting mixture, at the optimal values determined from preliminary experiments described under Materials and Methods. It was assessed that a fourth extraction cycle did not increase $\left[{ }^{14} \mathrm{C}\right]$-ETD recoveries in the naturally aged sample used.

As shown in Table 1, extracted ${ }^{14} \mathrm{C}$ activity increased by increasing water content of methanol or acetonitrile. For acetone, a slight decrease was observed when the amount of water reached $60 \%$. This effect had been already reported for the extraction of some pesticides from soils $(32,36) . \mathrm{ACN} / \mathrm{H}_{2} \mathrm{O}$ $87: 13 \mathrm{v} / \mathrm{v}$ and acetone $/ \mathrm{H}_{2} \mathrm{O} 60: 40 \mathrm{v} / \mathrm{v}$ were found to be the more efficient mixtures for cold shaking extraction. In the corresponding HPLC- $-{ }^{14} \mathrm{C}$ chromatograms (Figure 2), part of the applied ETD has been transformed into A-ETD and two other unknown compounds (Y, Z). This transformation did not occur during the extraction procedure as controls (ETD solutions prepared in uncontaminated soil extract) were found to be stable for more than one night at room temperature. It was consequently attributed to natural degradation in soil before sample 
Table 1. Influence of Extractant Composition and Extraction Method on $\left[{ }^{14} \mathrm{C}\right]-\mathrm{ETD}$ Activity and HPLC-UV Concentration of the Pesticides in the Extracts

\begin{tabular}{|c|c|c|c|c|}
\hline & \multicolumn{2}{|c|}{$\left[{ }^{14} \mathrm{C}\right]$-ETD activity $(\mathrm{Bq} / \mathrm{g}$ of dry wt) } & \multicolumn{2}{|c|}{ HPLC-UV concentrations (fexIKA) (mg L ${ }^{-1}$ ) } \\
\hline & shaking extraction & fluidized-bed hot extraction & ETD & MBT \\
\hline $\begin{array}{l}\mathrm{MeOH} \\
\mathrm{MeOH} / \mathrm{H}_{2} \mathrm{O} 80: 20 \mathrm{v} / \mathrm{v} \\
\mathrm{MeOH} / \mathrm{H}_{2} \mathrm{O} 60: 40 \mathrm{v} / \mathrm{v}\end{array}$ & $\begin{array}{c}97.7 \pm 7.3(7.5 \%)^{a} \\
98.5 \pm 6.2(6.3 \%) \\
102.2 \pm 8.0(7.8 \%)\end{array}$ & $\begin{array}{c}n p^{b} \\
n p \\
162.0 \pm 18.8(11.6 \%)\end{array}$ & $\begin{array}{c}n p \\
n p \\
4.5 \pm 0.6(11.7 \%)\end{array}$ & $\begin{array}{c}n p \\
n p \\
1.0 \pm 0.2(22.9 \%)\end{array}$ \\
\hline $\begin{array}{l}\text { ACN } \\
\text { ACN/H } \mathrm{H}_{2} \mathrm{O} 87: 13 \mathrm{v} / \mathrm{v}\end{array}$ & $\begin{array}{l}128.1 \pm 6.8(5.3 \%) \\
133.7 \pm 1.6(1.2 \%)\end{array}$ & $\begin{array}{c}n p \\
166.1 \pm 9.8(5.9 \%)\end{array}$ & $\begin{array}{c}n p \\
3.7 \pm 1.4(36.5 \%)\end{array}$ & $\begin{array}{c}n p \\
0.60 \pm 0.33(55.0 \%)\end{array}$ \\
\hline $\begin{array}{l}\text { acetone } \\
\text { acetone } / \mathrm{H}_{2} \mathrm{O} \text { 80:20 v/v } \\
\text { acetone } / \mathrm{H}_{2} \mathrm{O} 60: 40 \mathrm{v} / \mathrm{v} \\
\text { acetone } / \mathrm{H}_{2} \mathrm{O} 40: 60 \mathrm{v} / \mathrm{v}\end{array}$ & $\begin{array}{c}92.4 \pm 6.0(6.5 \%) \\
100.5 \pm 7.6(7.6 \%) \\
132.4 \pm 1.7(1.3 \%) \\
128.7 \pm 15.7(12.2 \%)\end{array}$ & $\begin{array}{c}n p \\
n p \\
170.4 \pm 5.0(2.9 \%) \\
n p\end{array}$ & $\begin{array}{c}n p \\
n p \\
4.99 \pm 0.29(5.8 \%) \\
n p\end{array}$ & $\begin{array}{c}n p \\
n p \\
0.80 \pm 0.07(8.5 \%) \\
n p\end{array}$ \\
\hline
\end{tabular}

\footnotetext{
${ }^{a}$ Relative standard deviations are given in parentheses. ${ }^{b}$ Not performed.
}

collection. About $70 \%$ of extracted activity was recovered as ETD, $25 \%$ as A-ETD, and $5 \%$ as $\mathrm{Y}+\mathrm{Z}$ by extraction at room temperature. No A-MBT was detected by HPLC using UV detection, indicating that no significant degradation of MBT occurred, either naturally in the plot or during the extraction.

Fluidized-bed hot extraction improved total extracted activity by a factor of 1.2-1.6 (Table 1). Mean values obtained for $\left[{ }^{14} \mathrm{C}\right]$-ETD activity and MBT concentration did not significantly vary with solvent composition but were clearly more reproducible with acetone $/ \mathrm{H}_{2} \mathrm{O} 60: 40 \mathrm{v} / \mathrm{v}$. No thermal degradation of MBT was observed with this mixture by HPLC-UV. Moreover, as seen in HPLC $-{ }^{14} \mathrm{C}$ chromatograms (Figure 3), only A-ETD, ETD, Y, and $\mathrm{Z}$ were detected in acetone $/ \mathrm{H}_{2} \mathrm{O}$ 60:40 hot solvent extracts, with proportions identical to those found in cold shaking extracts. ETD was consequently stable in those conditions. On the contrary, a decrease of A-ETD and ETD, concomitant with the appearance of an unknown compound (called X), was observed in $\mathrm{ACN} / \mathrm{H}_{2} \mathrm{O}$ and $\mathrm{MeOH} / \mathrm{H}_{2} \mathrm{O}$ extracts, indicating that a thermal degradation of ETD and A-ETD had occurred. As shown in Figure 3, UV spectra of X and ETD exhibit similar trends but significantly different maxima. $\mathrm{X}$ was not further characterized as it was never observed in real samples collected in the field. Nevertheless, urea herbicides, such as phenylureas or MBT, are known to be thermally unstable: in a gas chromatograph, cleavage of the carbonyl group of MBT and A-MBT produces 2-(methylamino)benthiazole (formula I in Figure 1) $(9,37)$, and at elevated temperature diuron degrades into 3,4-dichloroaaniline (38). Rouchaud et al. (9) showed that 2-(methylamino)benthiazole exhibits a retention factor (Rf) of 0.16 , very close to that of A-MBT (0.17), on TLC silica plates (eluent: chloroform). The Rf values of the two compounds issued from demethylation of MBT and A-MBT in the 3-position of the urea group (formulas II and III in Figure 1) were very similar to one another but much lower (0.05 and 0.03$)$. It is consequently probable, by analogy, that $\mathrm{X}$ is 1-(5-ethylsulfonyl-1,3,4-thiadiazol-2-yl)methylamine (formula IV), whereas $\mathrm{Y}$ and $\mathrm{Z}$, produced from ETD in natural conditions, are 1(5-ethylsulfonyl-1,3,4-thiadiazol-2-yl)-1-methylurea and 1-(5ethylsulfonyl-1,3,4-thiadiazol-2-yl)urea (formulas V and VI).

The rate of A-ETD and ETD degradation was irreproducible, especially in $\mathrm{ACN} / \mathrm{H}_{2} \mathrm{O}$ medium (Table 2). HPLC-UV chromatograms were also more complex in that case, which made the integration of the MBT peak very difficult and explained the irreproducibility of MBT concentrations. It was then chosen to carry out further extractions using the fexIKA system and acetone $/ \mathrm{H}_{2} \mathrm{O} 60: 40 \mathrm{v} / \mathrm{v}$ as extractant.

HPLC Separation. An extract of the uncontaminated soil sample spiked with a mixture of A-ETD, ETD, A-MBT, and
MBT at relatively high level $\left(24 \mathrm{mg} \mathrm{L}^{-1}\right)$ was used to define the most appropriate conditions to resolve the pesticides and their metabolites from interferences. In preliminary experiments, acetonitrile and methanol were considered as possible organic solvents for elution. Several gradients starting from 5 and $10 \%$ $\mathrm{ACN}$ or $\mathrm{MeOH}$, with progressively decreasing slopes, were tested on a Purosphere column at different flow rates $(0.8-1.4$ $\left.\mathrm{mL} \min ^{-1}\right)$ and temperatures $\left(20-50{ }^{\circ} \mathrm{C}\right)$. The best result was achieved using $\mathrm{ACN} / \mathrm{H}_{2} \mathrm{O}$ as eluent at $0.8 \mathrm{~mL} \mathrm{~min}{ }^{-1}$ and $30^{\circ} \mathrm{C}$ with a 37 min linear step gradient starting with $5 \%$ ACN. Nevertheless, peaks of interest were not totally separated from their interferences in those conditions. A first $5 \mathrm{~min}$ isocratic step $\left(\mathrm{ACN} / \mathrm{H}_{2} \mathrm{O} 5: 95\right)$ before gradient elution helped to resolve the A-ETD peak. Moreover, acidification of the aqueous mobile phase by adding phosphoric acid ( $\mathrm{pH}$ 2.2) allowed improved peak profiles (broadening and symmetry) and, consequently, resolution in the A-ETD and ETD region. Chromatogram 1 of Figure 4A was obtained for an extract spiked at low concentration level with the four compounds $\left(0.45 \mathrm{mg} \mathrm{L}^{-1}\right)$ in the optimal elution conditions. Even in those conditions, A-MBT and MBT peaks were not totally resolved from their nearest peaks. Moreover, the existence of a tremendous baseline at these retention times prevented an excellent integration of the peaks. To improve selectivity, two possibilities were evaluated: the use of a more selective detection (fluorescence) and a purification of the extract before analysis.

Improvement of Selectivity. Use of a Fluorescence Detector. UV degradation of phenylurea herbicides produces dimethylamine as one of the products of photolysis (33). This amine reacts with orthophthalaldehyde-mercaptoethanol reagent to give a fluorophore that can be detected spectrofluorometrically. Fourteen phenylureas have been separated and detected in this way with a much better selectivity than UV detection systems and an adequate sensitivity for use as a residue method (39).

Due to the presence of urea groups in ETD and MBT as well as in their metabolites, UV degradation of these compounds produces also amines, which may react with OPA-MERC. Postcolumn photolysis and chemical derivatization were consequently envisaged for the determination of the four compounds. Reactors for UV degradation and postcolumn derivatization were homemade knitted coils in Teflon FEP and PTFE, respectively. Acetonitrile was replaced by methanol for chromatographic elution as it was formerly noticed that Teflon tubes become rapidly porous upon light exposure in the presence of ACN (40). HPLC gradient was adapted and the flow rate decreased to improve reaction yields. We studied the influence of the length and wall thickness of photolysis reactor on the intensities of chromatographic peaks. Different lengths for PTFE 

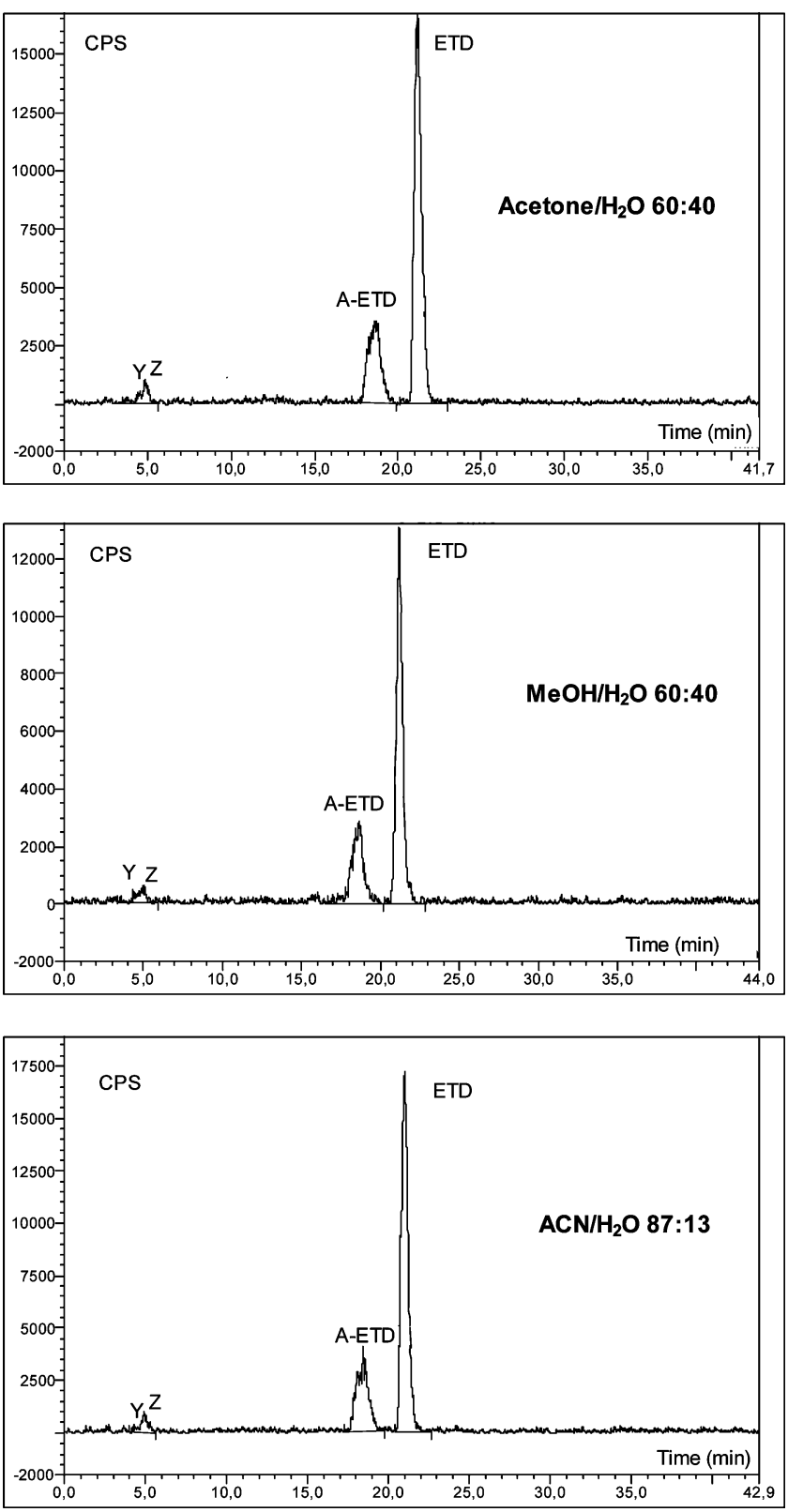

Figure 2. $\mathrm{HPLC}-{ }^{14} \mathrm{C}$ chromatograms of acetone $/ \mathrm{H}_{2} \mathrm{O} 60: 40, \mathrm{MeOH} / \mathrm{H}_{2} \mathrm{O}$ $60: 40$, and $\mathrm{ACN} / \mathrm{H}_{2} \mathrm{O} 87: 13$ extracts of a soil sample containing naturally aged residues of ${ }^{14} \mathrm{C}$-labeled ETD. Extraction conditions: shaking at room temperature for one night; sample mass, $25 \mathrm{~g}$; solvent volume, $150 \mathrm{~mL}$ column, Purosphere RP18 $1005 \mu \mathrm{m} ; T=30{ }^{\circ} \mathrm{C}$; flow rate, $0.6 \mathrm{~mL}$ $\mathrm{min}^{-1}$; linear $\mathrm{ACN} / \mathrm{H}_{2} \mathrm{O}$ step gradient, $5 \% \mathrm{ACN}$ for $5 \mathrm{~min}, 90 \%$ from 21 to $25 \mathrm{~min}$, and $5 \%$ at $32 \mathrm{~min}$.

reactor as well as several flow rates for HPLC and OPA-MERC were also tested for postcolumn derivatization. In the optimal conditions, given under Materials and Methods, ETD and MBT produced higher signals than A-ETD and A-MBT, which was attributed to their ability to degrade into monomethylamine, whereas their two demethylated derivatives produce mainly a less reactive secondary amine (formulas I and IV in Figure 1). Detection limits, calculated in matrix (soil extract) as 3 times the standard deviation of the background noise, were 20, 6, 70, and $14 \mu \mathrm{g} \mathrm{kg}^{-1}$ for A-ETD, ETD, A-MBT, and MBT, respectively. ETD and MBT values were comparable to that reported for some phenylureas in food samples $\left(1-6 \mu \mathrm{g} \mathrm{kg}^{-1}\right)$ (33). Nevertheless UV detection allowed much lower results for the other compounds to be obtained. It was then decided to abandon postcolumn derivatization.
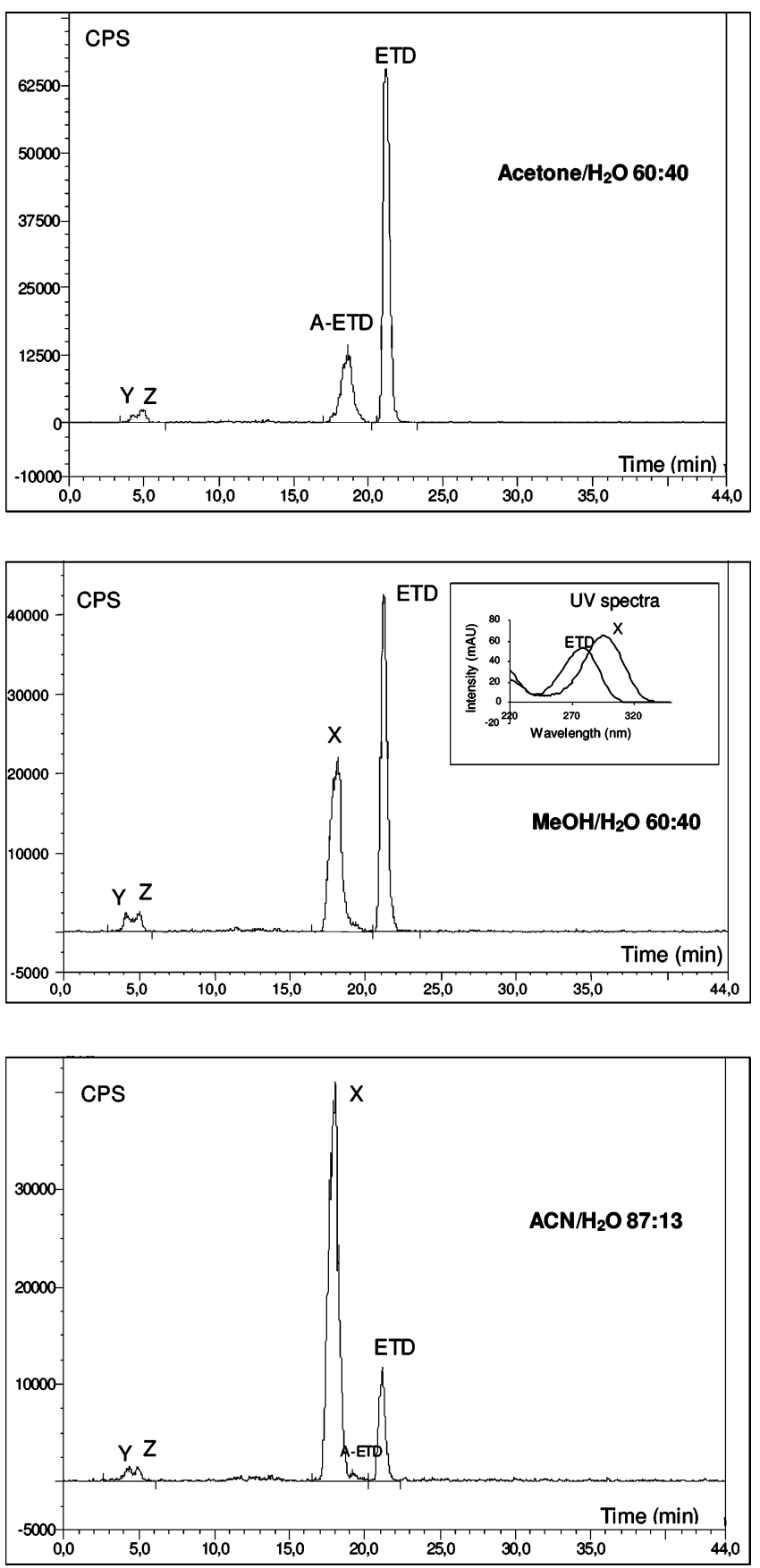

Figure 3. $\mathrm{HPLC}-{ }^{14} \mathrm{C}$ chromatograms of acetone $/ \mathrm{H}_{2} \mathrm{O} 60: 40, \mathrm{MeOH} / \mathrm{H}_{2} \mathrm{O}$ $60: 40$, and $\mathrm{ACN} / \mathrm{H}_{2} \mathrm{O} 87: 13$ extracts of a soil sample containing naturally aged residues of ${ }^{14} \mathrm{C}$-labeled ETD. Extraction conditions: hot solvent extraction with fexIKA system; sample mass, $75 \mathrm{~g}$; solvent volume, 150 $\mathrm{mL}$. Chromatographic conditions are identical to those of Figure 2.

SPE Purification. First experiments were carried out on standard solutions containing the four compounds of interest in order to choose the best solvent to be used for sample dilution. $n$-Hexane, cyclohexane, toluene, dichloromethane, and ethyl acetate were tested. It appeared that the pesticides are only slightly soluble in cyclohexane or $n$-hexane and are not completely retained on the SPE column when they are dissolved in ethyl acetate. As a consequence, in the second series of experiments aiming to optimize the elution step, two standard solutions $\left(25 \mathrm{mg} \mathrm{L}^{-1}\right)$ were prepared by diluting a $1 \mathrm{~g} \mathrm{~L}^{-1}$ aqueous mixture of the compounds in DCM and toluene, respectively. Five milliliters of each was passed in duplicate through SPE cartridges and elution performed using EtOAc/ 
Table 2. HPLC-UV Concentrations of ETD, MBT, and Their Degradation Products in $\mathrm{ACN} / \mathrm{H}_{2} \mathrm{O}$ 87:13 v/v FexIKA Extracts

\begin{tabular}{cccccc}
\hline extract & $\begin{array}{c}X \\
\left(\mathrm{mg} \mathrm{L}^{-1}\right)\end{array}$ & $\begin{array}{c}\text { A-ETD } \\
\left(\mathrm{mg} \mathrm{L}^{-1}\right)\end{array}$ & $\begin{array}{c}\text { ETD } \\
\left(\mathrm{mg} \mathrm{L}^{-1}\right)\end{array}$ & $\begin{array}{c}\text { A-MBT } \\
\left(\mathrm{mg} \mathrm{L}^{-1}\right)\end{array}$ & $\begin{array}{c}\mathrm{MBT} \\
\left(\mathrm{mg} \mathrm{L}^{-1}\right)\end{array}$ \\
\hline 1 & $<\mathrm{LOD}$ & 1.5 & 4.8 & $<\mathrm{LOD}$ & 0.93 \\
2 & $<\mathrm{LOD}$ & 1.5 & 4.5 & $<\mathrm{LOD}$ & 1.1 \\
3 & $<\mathrm{LOD}$ & 1.2 & 4.5 & $<\mathrm{LOD}$ & 0.5 \\
4 & 0.61 & 1.1 & 4.5 & $<\mathrm{LOD}$ & 0.7 \\
5 & 1.6 & $<\mathrm{LOD}$ & 3.3 & $<\mathrm{LOD}$ & 0.5 \\
6 & 1.1 & $<\mathrm{LOD}$ & 4.6 & $<\mathrm{LOD}$ & 0.5 \\
7 & 3.2 & $<\mathrm{LOD}$ & 2.1 & $<\mathrm{LOD}$ & 0.6 \\
8 & 3.66 & $<\mathrm{LOD}$ & 0.91 & $<\mathrm{LOD}$ & $<\mathrm{LOQ}$ \\
\hline
\end{tabular}
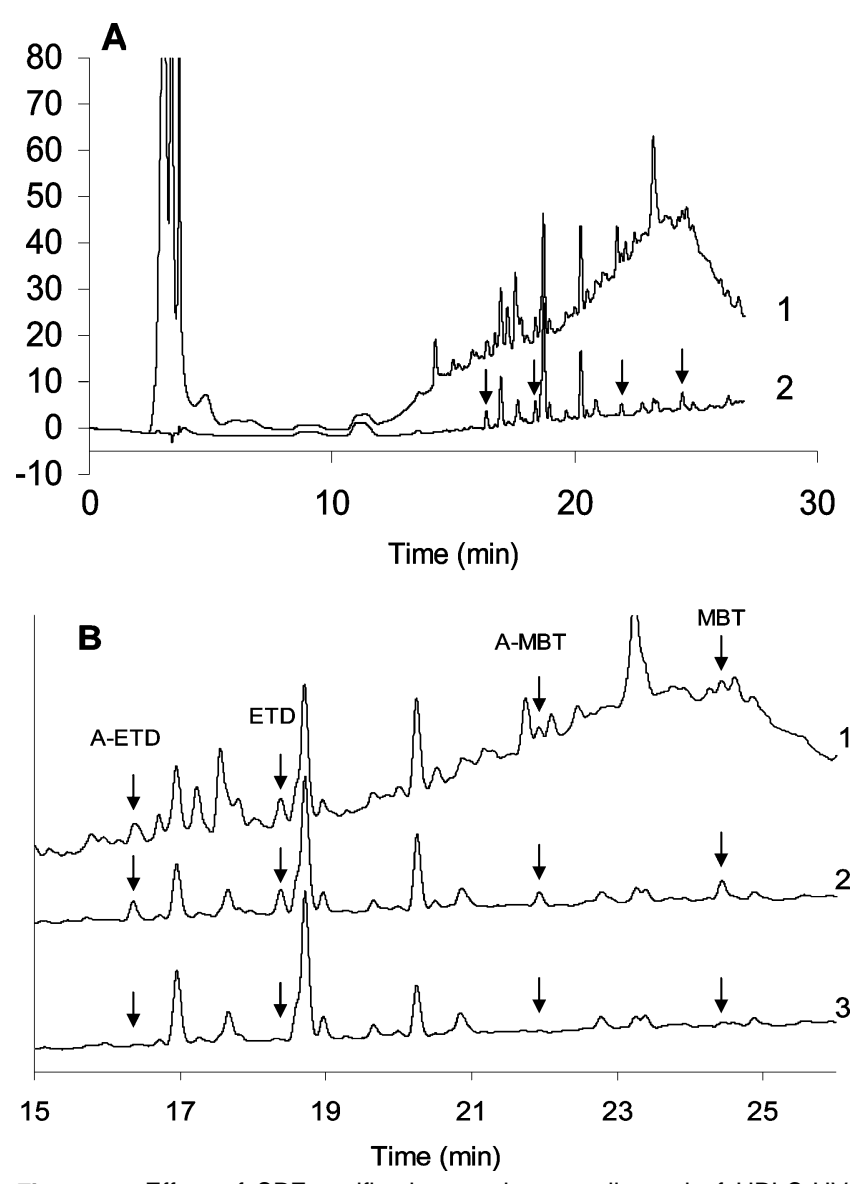

Figure 4. Effect of SPE purification on the overall trend of HPLC-UV chromatogram $(\mathbf{A})$ and on the resolution of A-ETD, ETD, A-MBT, and MBT peaks (B). Sample: surface soil extract spiked with the four compounds ( $0.45 \mathrm{mg} \mathrm{L}^{-1}$ corresponding to $12 \mu \mathrm{g} \mathrm{kg}^{-1}$ of soil) without (1) or with (2) purification. (3) is the chromatogram of the purified raw extract. HPLC conditions are given under Materials and Methods.

DCM and EtOAc/toluene. Different solvent ratios (80:20, 60: 40, 40:60, and 20:80 v/v) were tested in both cases. The best recoveries were obtained for an elution by EtOAc/DCM 60:40 (standards prepared in DCM) or EtOAc/toluene 80:20 (standards prepared in toluene). Nevertheless, only $10 \mathrm{~mL}$ is required in the first case and $20 \mathrm{~mL}$ in the second one. Toluene was then chosen to dissolve sample extracts. Washing of the column was achieved using DCM and elution using EtOAc/DCM 60:40. However, in the first experiments carried out under those conditions, some solutions obtained after dissolution of the extracts in pure toluene were cloudy due to the incomplete dissolution of ETD or MBT in the presence of matrix components. It was shown that the addition of a small volume of water (20 $\mu \mathrm{L})$ was able to clarify the solutions.
Figure 4A shows that SPE purification considerably improves the baseline trend of the chromatogram. The baseline is roughly flat and does not disturb integration anymore. In those conditions, no significant peak was detected in the purified matrix at retention times corresponding to A-ETD, ETD, A-MBT, and MBT, and the four peaks were well separated in the chromatogram corresponding to the fortified extract (Figure 4B).

Method Performance. Tables 3 and $\mathbf{4}$ summarize the main analytical figures of merit of the method, determined in the optimal conditions previously defined.

Characteristics of the HPLC-DAD Method. As seen in Table 3 , relative standard deviations of retention times are always $<0.6 \%$, demonstrating the excellent reproducibility of the chromatographic separation. The slopes of the calibration curves built from seven standards $\left(0.5-50 \mathrm{mg} \mathrm{L}^{-1}\right)$ prepared in ACN/ $\mathrm{H}_{2} \mathrm{O} 50: 50$ or in matrix are not significantly different at the 95\% confidence level, proving the absence of matrix effect. Intercepts are also not significantly different from 0 . Curves are linear as regression coefficients $r^{2}$ are always $>0.999$, and the $F$ test for lack of fit (ANOVA) is not significant at the 5\% level $\left(F_{1}\right.$ always found to be lower than $\left.F_{(0.05 ; 5,14)}=2.96\right)$.

Extraction Recoveries. ETD and MBT extraction recoveries were calculated in the optimal conditions using surface soil samples $\mathrm{A}-\mathrm{F}$ fortified with individual ${ }^{14} \mathrm{C}$-radiolabeled compounds in the $15-450 \mu \mathrm{g} \mathrm{kg}^{-1}$ concentration range. Recoveries were always found to be slightly lower for MBT than for ETD but were $>90 \%$ and reproducible and did not significantly depend on concentration level (data not shown). They were consequently pooled for each compound to give the mean values and related standard deviations presented in Table 4. The influence of soil aging was studied on soils B and $\mathrm{C}$ spiked at medium concentration levels $(80-100 \mu \mathrm{g} \mathrm{kg}-1)$. Mean ${ }^{14} \mathrm{C}$ activities recovered at the end of the 6 month storage period represented 102 and 94\% of added values, respectively. Thus, soil aging did not influence ETD or MBT extractability in a significant way.

In order to control that extraction recoveries not be overestimated due to the spiking mode chosen (32), two soil samples fortified at the $40 \mu \mathrm{g} \mathrm{kg}^{-1}$ level according to a batch equilibrium method (procedure 2) were extracted. Values were $96 \%$ for ETD and $88 \%$ for MBT, comparable to recoveries found for soils A and $\mathrm{E}$, fortified at the same concentration level but following procedure $1(98 \pm 5$ and $90 \pm 7 \%, n=8)$.

Comparison of those results with literature data must be carried out very carefully, because the composition of the soil, which differs from one work to another, may affect in a very significant way its binding capacity and therefore the extractability of the compounds. Jarczyk et al. reported ETD recoveries of $80-99 \%$ for a soil of similar properties (clay content, $15.3 \%$; organic content, $1.36 \% ; \mathrm{pH} 6.1$ ), spiked at four different concentrations (50-1000 $\mu \mathrm{g} \mathrm{kg}^{-1}$ ) and extracted by mechanical shaking with acetone/water and chloroform. For MBT, which binds very tightly with the organic components of the soil, recoveries between 80 and $100 \%$ were obtained by microwaveassisted solvent extraction of freshly spiked soils (450-1800 $\left.\mu \mathrm{g} \mathrm{kg}^{-1}\right)$, the lowest values being obtained for samples of high organic matter contents (32). Soil aging only slightly influenced recovery results. For a sample with characteristics close to that of the Merzenhausen soil (organic matter, 1.4\%; pH 7.2; CEC, 18 mequiv $100 \mathrm{~g}^{-1} ; K_{\mathrm{f}, \mathrm{MBT}}=5.3 \mathrm{~cm}^{3} \mathrm{~g}^{-1}$ ) and spiked at a 150 $\mu \mathrm{g} \mathrm{kg}^{-1}$ level, MBT recovery was $104 \%$ without aging and $93 \%$ after a storage period of 150 days at $4{ }^{\circ} \mathrm{C}$.

From this study, it may be concluded that FBE is a very capable method for MBT and ETD extraction, comparable to 
Table 3. Characteristics of the HPLC-DAD Method

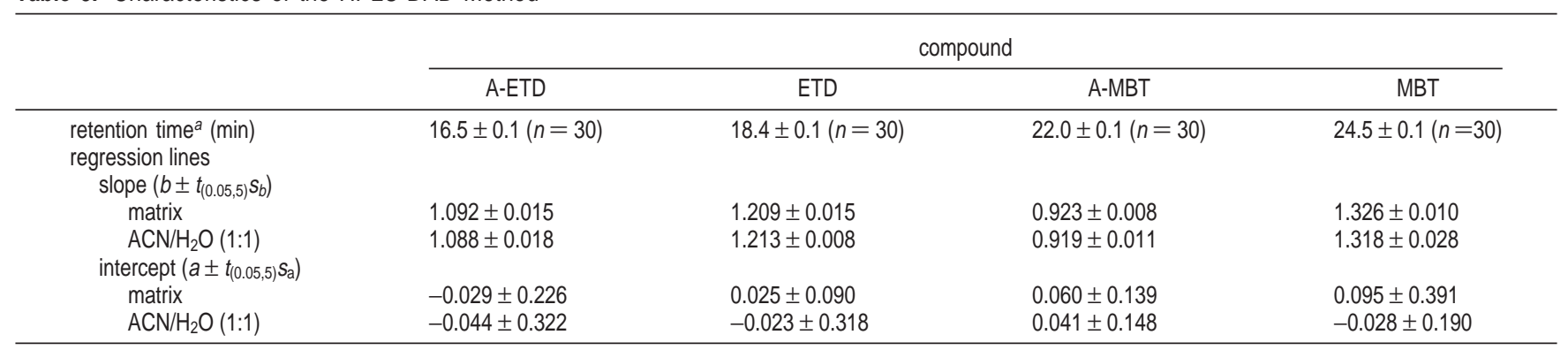

${ }^{a}$ From 10 injections on three different days of a $25 \mathrm{mg} \mathrm{L}^{-1}$ standard solution.

Table 4. Performance of the Whole Method

\begin{tabular}{|c|c|c|c|c|}
\hline & \multicolumn{4}{|c|}{ compound } \\
\hline & A-ETD & ETD & A-MBT & MBT \\
\hline concentration range $\left(\mu \mathrm{g} \mathrm{kg}^{-1}\right.$ of dry wt) & $32-158$ & $19-103$ & $35-171$ & $15-453$ \\
\hline mean recovery ${ }^{c}(\%)$ & $96.3-98.5$ & $97.0-103.3$ & $95.5-96.9$ & $93.3-103.7$ \\
\hline $\operatorname{RSD}^{c}(\%)$ & $3.8-6.3$ & $3.9-5.5$ & $2.7-5.9$ & $3.2-5.1$ \\
\hline LOD ( $\mu \mathrm{g} \mathrm{kg}^{-1}$ of dry wt) & 2.4 & 2.1 & 1.9 & 2.9 \\
\hline $\mathrm{LOQ}\left(\mu \mathrm{g} \mathrm{kg}^{-1}\right.$ of dry wt) & 8.5 & 8.0 & 8.0 & 9.6 \\
\hline
\end{tabular}

${ }^{a}$ Calculated as mean ${ }^{14} \mathrm{C}$-activity recovery from eight extracts of soil samples $A$ and $B(E T D)$ or $\mathrm{C}-\mathrm{F}(\mathrm{MBT}) .{ }^{b}$ Calculated as mean ${ }^{14} \mathrm{C}$-activity recovery from extracts fortified with radiolabeled compounds at two concentration levels ( 0.77 and $6.8 \mathrm{mg} \mathrm{L}^{-1}$ for ETD; 0.51 and $5.2 \mathrm{mg} \mathrm{L}^{-1}$ for MBT) and purified in triplicate. ${ }^{c}$ From four extracts of freshly spiked soil samples; two aliquots purified for each extract and analyzed in duplicate by HPLC-DAD for three consecutive days
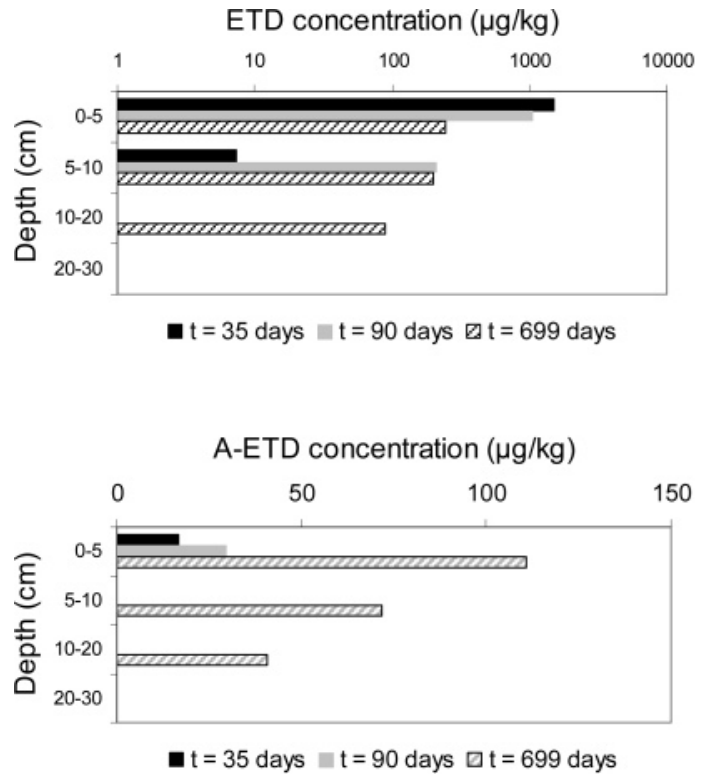
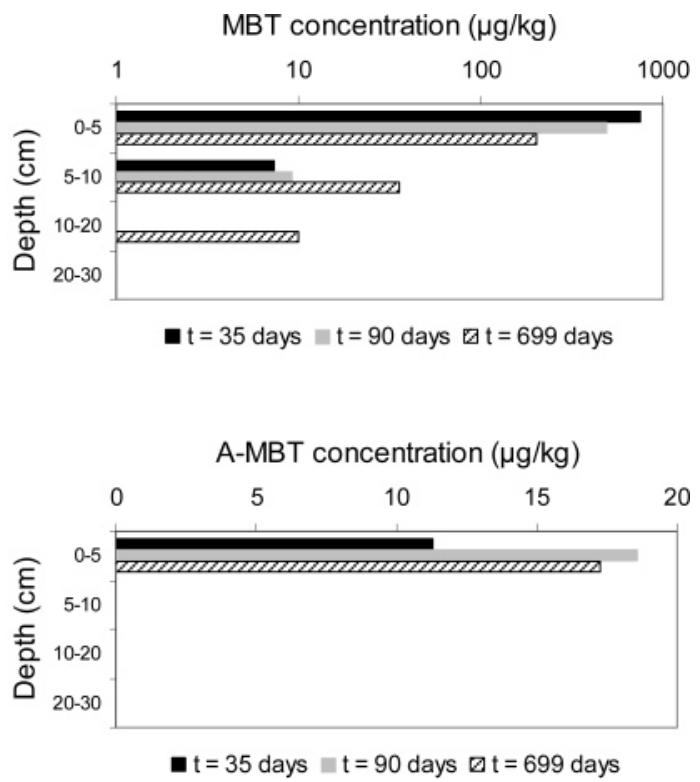

Figure 5. Evolution of the concentration profiles in the first $30 \mathrm{~cm}$. Soil samples were collected in the field after application of both ETD $\left(1.4 \mathrm{~kg}^{-1}\right.$ ha and MBT $\left(1.6 \mathrm{~kg} \mathrm{ha}^{-1}\right)$.

microwave-assisted solvent extraction. A statistical test showed that extraction recoveries are close to but significantly different from $100 \%$ at the $95 \%$ confidence level. It was then decided to apply correction factors of 0.964 and 0.900 to ETD and MBT HPLC concentrations in further calculations. As no ${ }^{14} \mathrm{C}$-labeled A-ETD and A-MBT were available, it was not possible to calculate extraction yields for those compounds. They were assumed to be identical to that of ETD and MBT, respectively. This assumption was verified during the validation process, as the overall recovery of the method (including extraction but also purification and determination) was close to $100 \%$ for both metabolites after correction by extraction efficiencies (see overall method performance part).
Cleanup Recoveries. Cleanup recoveries were evaluated using extracts spiked with radiolabeled ETD or MBT at two concentration levels (corresponding to about 2 and 20 times the quantification limit) and purified in triplicate. As for extraction recoveries, values did not significantly depend on concentration level and were pooled to give the average figures and related standard deviations given in Table 4. As they were not found to be significantly different from $100 \%$ at the $95 \%$ confidence level, no additional correction factor was applied to HPLC results.

Accuracy and Precision of the Overall Method. As presented in Table 4, overall recoveries from freshly spiked samples do not significantly depend on concentration level and are close 
to $100 \%$ after correction by extraction efficiencies. Mean recoveries of aged residues of MBT and ETD were also close to $100 \%$ : $102 \%$ (soil B) and $95.7 \%$ (soil C). Moreover, RSD values were found to lie between 2.7 and $6.3 \%$, showing that spiking is homogeneous and demonstrating the excellent accuracy and precision of the method.

Limits of Detection (LOD) and Quantification (LOQ). LOD and LOQ were found to be quite identical for the four analytes (2-3 $\mu \mathrm{g} \mathrm{kg}^{-1}$ for LOD and $8-9 \mu \mathrm{g} \mathrm{kg}^{-1}$ for LOQ). These values are comparable to that obtained for linuron and other phenylureas (41) or for sulfonylureas (42) extracted by microwave-assisted solvent extraction and determined by HPLCDAD. Baez et al. reported a much higher value for MBT (47 $\mu \mathrm{g} \mathrm{kg}^{-1}$ ), but it was obtained without purification for a higher ratio between final volume and sample mass. Quite lower limits of quantification $\left(0.7-4.5 \mu \mathrm{g} \mathrm{kg}^{-1}\right)$ were also reported for phenylureas by LC-APCI/MS/MS following pressurized liquid extraction (43). No cleanup was required and MS, contrary to UV, allowed a confirmation of the residues. Nevertheless, extraction and quantification techniques are far more costly.

Application to Soils Treated with ETD and MBT. Soil samples were collected from the field at several depths (0$120 \mathrm{~cm})$ and at different times $(35,90,145,218,341,532$, and 699 days) after application of both ETD $\left(1.4 \mathrm{~kg} \mathrm{ha}^{-1}\right)$ and MBT (1.6 $\left.\mathrm{kg} \mathrm{ha}^{-1}\right)$. They were analyzed following the overall methodology developed above. HPLC-ES-MS/MS analysis of some samples containing low concentrations of the pesticides or their metabolites (typically $10-30 \mathrm{~g} \mathrm{~kg}^{-1}$ ), collected at $t=$ 90 days, allowed confirmation of the residues at low levels.

Pesticides and their metabolites were mainly found in the first $30 \mathrm{~cm}$. Figure 5 shows, as an illustration, the corresponding concentration profiles 35, 90, and 699 days after treatment (mean of 21-33 samples collected at each soil layer). A significant (but relatively low) demethylation of both pesticides is observed as of the first sampling day. Contrary to A-ETD, A-MBT remains mainly in the top layer $(0-5 \mathrm{~cm})$ and its concentration is quite constant with time $\left(\approx 10 \mu \mathrm{g} \mathrm{kg}^{-1}\right)$. ETD and MBT concentrations decrease with time, more rapidly for ETD than MBT, but are still high ( $>100 \mu \mathrm{g} \mathrm{kg}^{-1}$ ) even after 699 days. Contrary to MBT, ETD is also observed in the $10-20 \mathrm{~cm}$ after 2 years. These results confirm that both pesticides are relatively stable and persistent in soil, but MBT and ETD behaviors (sorption and degradation) are different, in agreement with literature data.

Conclusions. FBE is an efficient and fully automated technique for the extraction for the four compounds of interest, more rapid than classical Soxhlet and shaking methods. Using the protocol developed in this work, it was possible to determine the four compounds at a low concentration level $\left(10 \mu \mathrm{g} \mathrm{kg}^{-1}\right)$ in a relatively short time. Soil samples containing aged residues were also extracted very efficiently with an excellent precision, and the methodology was successfully applied to the determination of the analytes in real samples. In the future, it will nevertheless be interesting to reduce the relatively high volumes of solvent needed for extraction. This will be possible by developing a miniaturized apparatus, which will allow extractions with $10-20 \mathrm{~mL}$ of solvent. This equipment is not yet commercially available but is necessary to make the technique more competitive with other enhanced techniques such as microwave-assisted or high-pressure solvent extraction.

\section{ACKNOWLEDGMENT}

We thank S. Dohmen and S. Köppchen for their precious technical assistance

\section{LITERATURE CITED}

(1) Pütz, Th.; Brumhard, B.; Dressel, J.; Kaiser, R.; Wüstemeyer, A.; Scholz, K.; Schäfer, H.; König, Th.; Führ, F. FELS: a comprehensive approach to studying the fate of pesticides in soil at the laboratory, lysimeter and field scales. In The Lysimeter Concept: Environmental Behavior of Pesticides; Fuhr, F., Hance, R. J., Plimmer, J. R., Nelson J. O., Eds.; ACS Symposium Series 699; American Chemical Society: Washington, DC, 1998; pp $152-162$.

(2) Thompson, H. E.; Swanson, C. P.; Norman, A. G. New growthregulating compounds. I. Summary of growth-inhibitory activities of some organic compounds as determined by three tests. Bot. Gaz. 1946, 107, 476-507.

(3) The Pesticide Manual, 10th ed.; Tomlin, C., Ed.; The British Crop Protection Council and The Royal Society of Chemistry: London, U.K., 1994.

(4) Cheng, H. H.; Führ, F. Extraction of methabenzthiazuron from the soil. J. Agric. Food Chem. 1976, 24, 421-424.

(5) Mittelstaedt, W.; Still, G. G.; Dürbeck, H.; Führ, F. Extraction and identification of the major metabolite of [carbonyl- $\left.{ }^{14} \mathrm{C}\right]-$ methabenzthiazuron after degradation in the soil. J. Agric. Food Chem. 1977, 25, 908-917.

(6) Cheng, H. H.; Führ, F. Degradation of methabenzthiazuron in the soil. J. Agric. Food Chem. 1978, 26, 595-599.

(7) Kubiak, R.; Führ, F.; Mittelstaedt, W.; Hansper, W.; Steffens, W. Transferability of lysimeter results to actual field situations. Weed Sci. 1988, 36, 514-518.

(8) Pütz, Th.; Mittelstaedt, W.; Führ, F. Seasonal changes of [phenyl$\left.\mathrm{U}-{ }^{14} \mathrm{C}\right]$ methabenzthiazuron loads in soil under practical farming conditions. Chemosphere 1998, 37, 1531-1545.

(9) Rouchaud, J.; Roucourt, P.; Van Himme, M.; Benoit, F.; Ceustermans, N.; Gillet, J.; Plumier, W.; Vulsteke, G. Metabolism of methabenzthiazuron in the soil of pea crops. J. Agric. Food Chem. 1988, 36, 642-645.

(10) Printz, H.; Burauel, P.; Führ, F. Effect of organic amendment on degradation and formation of bound residues of methabenzthiazuron in soil under constant climatic conditions. J. Environ. Sci. Health 1995, B30 (4), 435-456.

(11) Berger, B. M.; Bernd, T.; Menne, H. J.; Hackfeld, U.; Siebert, C. F. Effects of crop management on the fate of three herbicides in soil. J. Agric. Food Chem. 1996, 44, 1900-1905.

(12) Baez, M. E.; Rodriguez, M.; Vilches, P.; Romero, E. Adsorption of methabenzthiazuron on six allophanic and nonallophanic soils: effect of organic matter amendment. J. Environ. Sci. Health 2001, B36 (1), 95-105.

(13) Wallnoefer, P.; Tillmanns, G.; Thomas, R.; Wünsche, C.; Kurz, J.; Jarczyk, H. J. Mikrobieller Abbau des Herbizid methabenzthiazuron und identifizierung der Metaboliten. Chemosphere 1976, 5, 377-382.

(14) Goettfert, J.; Parlar, H.; Korte, F. Microbial transformation of $\left[{ }^{14} \mathrm{C}\right]$ methabenzthiazuron by the soil fungus Hypocrea $\mathrm{Cf}$ pilulifera Webster St Con: isolation, identification and characterization of some metabolites from the chloroform extract. J. Agric. Food Chem. 1978, 26, 628-632.

(15) Malouki, M. A.; Giry, G.; Besse, P.; Combourieu, B.; Sancelme, M.; Bonnemoy, F.; Richard, C.; Delort, A. M. Sequential bioand phototransformation of the herbicide methabenzthiazuron in water. Environ. Toxicol. Chem. 2003, 22, 2013-2019.

(16) Kerpen, W. Das Verhalten des Herbizid ethidimuron in 12 Böden; Report 11/78; KFA: Jülich, Germany, 1978.

(17) Hawkins, D. R.; Elsom, L. F.; Weston, K. T. The biodegradation of the herbicide ethidimuron in soil; Report; Huntingdon Research Center: Huntingdon, Cambridgeshire, U.K., 1979.

(18) Putzien, J. Über die Bestimmung von Pflanzenschutzmitteln in Trinkwasser mit Hilfe der HPLC. Z. Wasser-Abwasser-Forsch. 1986, 19, 228-236.

(19) Reupert, R.; Brausen, G.; Schuster, R. Determination of pesticides in water by on-line solid-phase extraction and HPLC-DAD. Acta Hydrochim. Hydrobiol. 1998, 26, 318-329. 
(20) Jarczyk, H. J. Method for gas-chromatographic determination of Ustilan residues in soil and water, with an $\mathrm{N}$-specific detector. Pflanzenschutz-Nachr. Bayer 1979, 32, 186-195.

(21) Eremin, S. A.; Mel'nichenko, O. A.; Kreissig, S.; Hock, B. Rapid immunochemical method for the determination of herbicide methabenzthiazuron. J. Anal. Chem. 1995, 50, 971-978.

(22) Berrada, H.; Molto, J. C.; Font, G. Gas chromatographic behavior of urea herbicides. Chromatographia 2001, 54, 360-364.

(23) Stan, H. J.; Klaffenbach, P. Determination of thermolabile urea pesticides after derivatization with BFA using GC-ECD and confirmation by means of GC-MSD. Fresenius' J. Anal. Chem. 1991, 339, 40-45.

(24) Scott, S. Determination of derivatized urea herbicides in water by solid-phase extraction, methylation and gas chromatography with nitrogen-phosphorus detector. Analyst 1993, 118, 11171122.

(25) Rodriguez, R.; Pico, Y.; Font, G.; Manes, J. Determination of urea-derived pesticides in fruits and vegetables by solid-phase preconcentration and capillary electrophoresis. Electrophoresis 2001, 22, 2010-2016.

(26) Jeannot, R.; Sabik, H.; Sauvard, E.; Genin, E. Application of liquid chromatography with mas spectrometry combined with photodiode array detection and tandem mass spectrometry for monitoring pesticides in surface waters. J. Chromatogr. A 2000, $879,51-71$

(27) Van der Heeft, E.; Dijkman, E.; Baumann, A.; Hogendoorn, E. A. Comparison of various liquid chromatographic methods involving UV and atmospheric pressure chemical ionization mass spectrometric detection for the efficient trace analysis of phenylurea herbicides in various types of water samples. J. Chromatogr. A 2000, 879, 39-50.

(28) Crescenzi, C.; Di Corcia, A.; Nazzari, M.; Samperi, R. Hot phosphate-buffered water extraction coupled on-line with liquid chromatography/mass spectrometry for analyzing contaminants in soil. Anal. Chem. 2000, 72, 3050-3055.

(29) Sanchez-Rasero, F.; Matallo, M.; Pena, A.; De la Colina, C.; Dios, G. C.; Romero, E. Liquid chromatographic determination of methabenzthiazuron in soil aqueous solutions with diode-array detection. J. Chromatogr. A 1996, 733, 367-370.

(30) Berger, B. Improved chromatographic method for the simultaneous determination of ten phenylurea herbicides and some of their degradation products in soil. J. Chromatogr. A 1997, 769, $338-342$.

(31) Vandecasteele, K.; Gaus, I.; Debreuck, W.; Walraevens, K. Identification and quantification of 77 pesticides in groundwater using solid-phase coupled to liquid-liquid microextraction and reversed-phase liquid chromatography. Anal. Chem. 2000, 72, 3093.

(32) Baez, M. E.; Aponte, A.; Sanchez-Rasero, F. Microwave-assisted extraction of the herbicide methabenzthiazuron from soils and soil natural organic and inorganic constituents. Influence of environmental factors on its extractability. Analyst 2003, 128 , $1478-1484$

(33) Luchtenfeld, R. G. Multiresidue method for determining substituted urea herbicides in foods by liquid chromatography. $J$. Assoc. Off. Anal. Chem. 1987, 70 (4), 740-745.

(34) Grefer, M.; Serschen, M.; Lankmayr, E. Optimised extraction of polycyclic aromatic hydrocarbons from contaminated soil samples. J. Biochem. Biophys. Methods 2002, 53, 203-216.

(35) Martens, D.; Gfrerer, M.; Wenzl, T.; Zhang, A.; Gawlik, B. M.; Schramm, K. W.; Lankmayr, E.; Kettrup, A. Comparison of different extraction techniques fort he determination of polychlorinated organic compounds in sediment. Anal. Bioanal. Chem. 2002, 372, 562-568.

(36) Cotteril, E. G. The efficiency of methanol for the extraction of some herbicide residues from soil. Pestic. Sci. 1980, 11, 2328

(37) Berrada, H.; Molto, J. C.; Font, G. Gas chromatographic behavior of urea herbicides. Chromatographia 2001, 54 (5/6), 360-364.

(38) Salvestrini, S.; Di Cerbo, P.; Capasso, S. Kinetics of the chemical degradation of diuron. Chemosphere 2002, 48, 69-73.

(39) Kotzias, D.; Korte, F. Photochemistry of phenylurea herbicides and their reactions in the environment. Ecotoxicol. Environ. Saf. 1981, 5, 503-512.

(40) Werkhoven-Goewie, C. E.; Boon, W. M; Praat, A. J. J.; Brinkman, U. A. Th. preconcentration and LC analysis of chlorophenols using a styrene-divinyl-benzene copolymeric sorbent and photochemical reaction detection. Chromatographia 1982, 16, 53-59.

(41) Molins, C.; Hogendoorn, E. A.; Dijkman, E.; Heusinkveld, H. A. G.; Baumann, R. A. Determination of linuron and related compounds in soil by microwave-assisted solvent extraction and reverse-phase liquid chromatography with UV detection. $J$. Chromatogr. A 2000, 869, 487-496.

(42) Font, N.; Hernandez, F.; Hogendoorn, E. A.; Baumann, R. A.; Van Zoonen, P. Microwave-assisted solvent extraction and reverse-phase liquid chromatography-UV detection for screening soils for sulfonylurea herbicides. J. Chromatogr. A 1998, 798, $179-186$

(43) Dagnac, T.; Bristeau, S.; Jeannot, R.; Mouvet, C.; Baran, N. Determination of chloroacetanilides, triazines and phenylureas and some of their metabolites in soils by pressurised liquid extraction, GC-MS/MS, LC-MS and LC-MS/MS. J. Chromatogr. A 2005, 1067, 225-233.

Received for review April 13, 2006. Revised manuscript received July 12, 2006. Accepted July 12, 2006. We thank Bayer AG (Monheim, Germany) for their financial support.

JF061042V 